\title{
Hypertension Among Youths — United States, 2001-2016
}

\author{
Sandra L. Jackson, $\mathrm{PhD}^{1}$; Zefeng Zhang, MD, $\mathrm{PhD}^{1}$; Jennifer L. Wiltz, MD ${ }^{1,2}$; Fleetwood Loustalot, $\mathrm{PhD}^{1,2}$; Matthew D. Ritchey, DPT ${ }^{1,2}$; \\ Alyson B. Goodman, $\mathrm{MD}^{3}$; Quanhe Yang, $\mathrm{PhD}^{1}$
}

Hypertension is an important modifiable risk factor for cardiovascular morbidity and mortality, and hypertension in adolescents and young adults is associated with long-term negative health effects $(1,2){ }^{*}$ In 2017, the American Academy of Pediatrics (AAP) released a new Clinical Practice Guideline (3), which updated 2004 pediatric hypertension guidance ${ }^{\dagger}$ with new thresholds and percentile references calculated from a healthy-weight population. To examine trends in youth hypertension and the impact of the new guideline on classification of hypertension status, CDC analyzed data from 12,004 participants aged 12-19 years in the 2001-2016 National Health and Nutrition Examination Survey (NHANES). During this time, prevalence of hypertension declined, using both the new (from $7.7 \%$ to $4.2 \%, \mathrm{p}<0.001$ ) and former (from $3.2 \%$ to $1.5 \%, \mathrm{p}<0.001)$ guidelines, and declines were observed across all weight status categories. However, because of the new percentile tables and lower threshold for hypertension (4), application of the new guideline compared with the former guideline resulted in a weighted net estimated increase of 795,000 U.S. youths being reclassified as having hypertension using 2013-2016 data. Youths who were older, male, and those with obesity accounted for a disproportionate share of persons reclassified as having hypertension. Clinicians and public health professionals might expect to see a higher prevalence of hypertension with application of the new guideline and can use these data to inform actions to address hypertension among youths. Strategies to improve cardiovascular health include adoption of healthy eating patterns and increased physical activity (3).

NHANES is a nationally representative survey of noninstitutionalized persons in the United States. The survey includes an in-person examination with up to three brachial systolic blood pressure (SBP) and diastolic blood pressure (DBP) readings taken by certified examiners. Mean SBP and DBP values were used. ${ }^{\S}$ Among 13,523 participating youths during

\footnotetext{
*https://www.nhlbi.nih.gov/files/docs/peds_guidelines_sum.pdf.

$\dagger$ National High Blood Pressure Education Program Working Group on High Blood Pressure in Children and Adolescents. The Fourth Report on the Diagnosis, Evaluation, and Treatment of High Blood Pressure in Children and Adolescents. https://www.nhlbi.nih.gov/files/docs/resources/heart/hbp_ped.pdf.

$\S$ A maximum of three blood pressure readings were measured for each participant in the Mobile Examination Center under a standard protocol. For participants with only a single $\mathrm{BP}$ reading, that measurement was used in place of an average. https://wwwn.cdc.gov/nchs/data/nhanes/2013-2014/manuals/Phys_Exam_ Manual_2013.pdf.
}

2001-2016, those missing SBP or DBP (999), or body mass index (BMI $\left.\left[\mathrm{kg} / \mathrm{m}^{2}\right]\right)(136)$ were excluded. In addition, youths classified as underweight (BMI-for-age $<5$ th percentile; 384) were excluded because of insufficient sample size, leaving 12,004 persons aged 12-19 years in the analytic sample.

Elevated blood pressure (BP) and hypertension were defined according to age-specific thresholds established in both the former and new guidelines. To apply the former guideline, among those aged 12-17 years, elevated BP (formerly "prehypertension") was defined as $\mathrm{BP} \geq 90$ th to $<95$ th percentile or $\geq 120 / 80 \mathrm{mmHg}$ to $<95$ th percentile; hypertension was defined as $\mathrm{BP} \geq 95$ th percentile (using 2004 age, sex, and height-specific percentile tables) or reported antihypertensive medication use (only available for persons aged $>15$ years) (Supplementary Table 1, https://stacks.cdc.gov/view/cdc/56579). Among persons aged 18-19 years, elevated BP was defined as SBP $\geq 120 \mathrm{mmHg}$ to $<140 \mathrm{mmHg}$ or $\mathrm{DBP} \geq 80 \mathrm{mmHg}$ to $<90 \mathrm{mmHg}$; hypertension was defined as BP $\geq 140 / 90 \mathrm{mmHg}$ or reported antihypertensive medication use.

The new guideline used new percentile tables (from a reference population excluding youths with overweight/obesity). To apply the new guideline, among adolescents aged $12-17$ years, elevated $\mathrm{BP}$ was defined as $\mathrm{BP} \geq 90$ th to $<95$ th percentile or $\mathrm{SBP} \geq 120 \mathrm{mmHg}$ to $<95$ th percentile; hypertension was defined as $\mathrm{BP} \geq 95$ th percentile, $\mathrm{BP} \geq 130 / 80 \mathrm{mmHg}$, or reported antihypertensive medication use. For persons aged 18-19 years, elevated $\mathrm{BP}$ was defined as $\mathrm{SBP} \geq 120 \mathrm{mmHg}$ to $<130 \mathrm{mmHg}$ and DBP $<80 \mathrm{mmHg}$; hypertension was defined as $\mathrm{BP} \geq 130 / 80 \mathrm{mmHg}$ or antihypertensive medication use. The new guideline thresholds for persons aged 18-19 years align

\footnotetext{
From NHANES Prescription Medication dataset, unpublished. The definition of hypertension used in this analysis did not include medications identified as being antihypertensives in the Prescription Medication dataset (in which interviewers asked to see all prescription medication containers for medications that the participant had taken within 30 days), because some of these medications might not have been taken for the purpose of controlling hypertension. Hypertension in this analysis only included self-reported antihypertensive use from the Blood Pressure and Cholesterol Module (e.g., "Because of your high blood pressure/hypertension, have you ever been told to take prescribed medicine?"). However, use of medications identified as being antihypertensives in the Prescription Medication dataset increased from 2001 to 2014, the last year for which this dataset was available.
} 
with recommendations in the 2017 Hypertension Clinical Practice Guideline for persons aged $\geq 18$ years.**

Weight status was categorized using age- and sex-specific reference values from the $2000 \mathrm{CDC}$ growth charts ${ }^{\dagger \dagger}$ (healthy weight: BMI-for-age $\geq 5$ th to $<85$ th percentiles; overweight: $\geq 85$ th to $<95$ th; obesity: $\geq 95$ th). In addition, a subset of the group with obesity (severe obesity, defined as BMI-for-age $\geq 120 \%$ of the 95 th percentile) was examined (5). Race/ethnicity was classified as non-Hispanic white, non-Hispanic black, Mexican American, and other. $\$ \$$

Participant characteristics across survey years were compared using Satterthwaite chi-squared tests and t-tests. Estimated prevalence of elevated BP, hypertension, and the combination of these were calculated in 4-year increments (to assure sufficient sample size) from 2001 to 2016, and trends were assessed using survey logistic regression adjusted for age, sex, and race/ethnicity. Using prevalence estimates from 2013 to

\footnotetext{
** Guideline for the Prevention, Detection, Evaluation, and Management of High Blood Pressure in Adults. A Report of the American College of Cardiology/American Heart Association Task Force on Clinical Practice Guidelines. http://hyper.ahajournals.org/content/early/2017/11/10/ HYP.0000000000000065.

${ }^{\dagger \dagger}$ https://www.cdc.gov/nccdphp/dnpao/growthcharts/resources/sas.htm.

$\$ \$$ During 1999-2006, certain groups, including Mexican Americans, were oversampled, while the number of non-Mexican American Hispanics in the NHANES sample was too small for reliable estimates. Because of these sampling differences and sample size concerns, it is not recommended to examine "all Hispanics" from years before 2007. Hispanics other than Mexican Americans were included in the "other" category. https://www.cdc.gov/nchs/ data/nhanes/analyticnote_2007-2010.pdf.
}

2016, population-level estimates of the number of youths classified as having hypertension were calculated. Bootstrap methodology with 1,000 resamples was used to estimate $95 \%$ confidence intervals for the percentage of the population reclassified as having hypertension. All analyses used exam sample weights and statistical procedures for complex surveys, and all tests were two-sided.

Population characteristics were mostly consistent from 2001 to 2016, although the prevalence of obesity increased from $17.8 \%(2001-2004)$ to $21.8 \%(2013-2016)(\mathrm{p}=0.016)$, as did the prevalence of severe obesity $(5.7 \%$ to $8.8 \%, p=0.003)$ (Table 1). During 2001-2016, the prevalence of hypertension declined, according to both the new (from $7.7 \%$ to $4.2 \%$, $\mathrm{p}<0.001$ ) and former (from $3.2 \%$ to $1.5 \%, \mathrm{p}<0.001$ ) guidelines (Figure) (Supplementary Table 2, https://stacks.cdc.gov/view/ cdc/56580). This decline occurred across all BMI categories, although the prevalence of hypertension was consistently highest among persons with obesity and severe obesity. During 2013-2016, using the new guideline, the prevalence of elevated $\mathrm{BP}$ was approximately $10 \%$, and the prevalence of combined elevated BP or hypertension was nearly 15\% (Figure).

Compared with the former guideline, the new guideline classified fewer youths with elevated BP and more youths as having hypertension (Figure). Using data from 2013 to 2016, an additional $2.6 \%$ of U.S. youths aged $12-19$ years would be reclassified as having hypertension, which translates to a net increase of approximately 795,000 persons (Table 2). Youths aged 18-19 years would account for approximately half of the

TABLE 1. Characteristics of youths aged 12-19 years - National Health and Nutritional Examination Survey (NHANES), United States, 2001-2016

\begin{tabular}{|c|c|c|c|c|c|}
\hline \multirow[b]{2}{*}{ Characteristic } & \multicolumn{4}{|c|}{$\%(95 \% \mathrm{Cl})$} & \multirow[b]{2}{*}{$\begin{array}{l}\text { P-value for } \\
\text { trend* }\end{array}$} \\
\hline & $\begin{array}{l}\text { NHANES 2001-2004 } \\
\quad(\mathrm{N}=4,169)\end{array}$ & $\begin{array}{l}\text { NHANES 2005-2008 } \\
\quad(\mathrm{N}=3,076)\end{array}$ & $\begin{array}{l}\text { NHANES 2009-2012 } \\
\quad(\mathrm{N}=2,319)\end{array}$ & $\begin{array}{l}\text { NHANES 2013-2016 } \\
\quad(\mathrm{N}=2,440)\end{array}$ & \\
\hline \multicolumn{6}{|l|}{ Age group (yrs) } \\
\hline $12-17$ & $78.0(75.1-80.6)$ & $77.6(75.1-80.0)$ & $78.1(75.3-80.6)$ & 78.9 (76.9-80.8) & 0.539 \\
\hline $18-19$ & $22.0(19.4-24.9)$ & $22.4(22.0-24.9)$ & $21.9(19.4-24.7)$ & $21.1(19.2-23.1)$ & \\
\hline \multicolumn{6}{|l|}{ Sex } \\
\hline Male & $50.8(48.9-52.7)$ & $51.5(49.2-53.9)$ & $50.8(48.2-53.4)$ & $50.4(48.0-52.8)$ & 0.703 \\
\hline Female & $49.2(47.3-51.1)$ & $48.5(46.1-50.8)$ & $49.2(46.6-51.8)$ & $49.6(47.2-52.0)$ & \\
\hline \multicolumn{6}{|l|}{ Race/Ethnicity } \\
\hline White, non-Hispanic & $63.2(57.6-68.5)$ & $61.7(56.6-66.6)$ & $56.5(50.4-62.3)$ & $54.0(46.7-61.2)$ & 0.024 \\
\hline Black, non-Hispanic & $14.0(11.2-17.4)$ & $15.2(11.9-19.2)$ & $15.0(11.5-19.4)$ & $14.1(10.5-18.6)$ & 0.987 \\
\hline Mexican American & $10.8(8.3-14.1)$ & $12.0(9.6-14.8)$ & $13.8(10.5-17.9)$ & $14.7(10.9-19.4)$ & 0.100 \\
\hline Other & $12.0(9.1-15.7)$ & $11.1(8.5-14.4)$ & $14.7(12.2-17.6)$ & $17.2(14.9-19.8)$ & 0.004 \\
\hline \multicolumn{6}{|l|}{ Weight status $^{\dagger}$} \\
\hline Healthy & $66.0(63.0-68.9)$ & $64.1(61.8-66.6)$ & $64.0(61.4-66.5)$ & $59.8(56.7-62.7)$ & 0.005 \\
\hline Overweight & $16.2(14.4-18.2)$ & $16.6(15.1-18.2)$ & $15.1(13.6-16.7)$ & $18.4(16.7-20.3)$ & 0.218 \\
\hline Obesity (all) & $17.8(15.8-19.9)$ & $19.2(16.8-21.9)$ & $20.9(18.9-23.2)$ & $21.8(19.0-24.9)$ & 0.016 \\
\hline Severe obesity & $5.7(4.6-7.1)$ & $6.6(5.2-8.3)$ & $7.5(5.8-9.7)$ & $8.8(7.3-10.6)$ & 0.003 \\
\hline
\end{tabular}

Abbreviations: $\mathrm{BMI}=$ body mass index; $\mathrm{Cl}$ = confidence interval.

* P-values for trends in participant characteristics across survey years were obtained using Satterthwaite chi-squared tests and t-tests. All tests were 2-tailed.

$+\mathrm{BMI}$ is compared with age- and sex-specific reference values from the 2000 CDC growth charts (https://www.cdc.gov/growthcharts/cdc_charts.htm). Healthy = BMIfor-age $\geq 5$ th to $<85$ th, overweight $=$ BMI-for-age $\geq 85$ th to $<95$ th percentile, obesity $=$ BMI-for-age $\geq 95 \%$ percentile. Severe obesity $=$ BMI-for-age $\geq 120 \%$ of the 95 th percentile. Persons classified as underweight (BMI-for-age $<5$ th percentile) are excluded. 
FIGURE. Prevalence of elevated blood pressure (BP) and hypertension among youths, by new and former guidelines - United States, 2001-2016

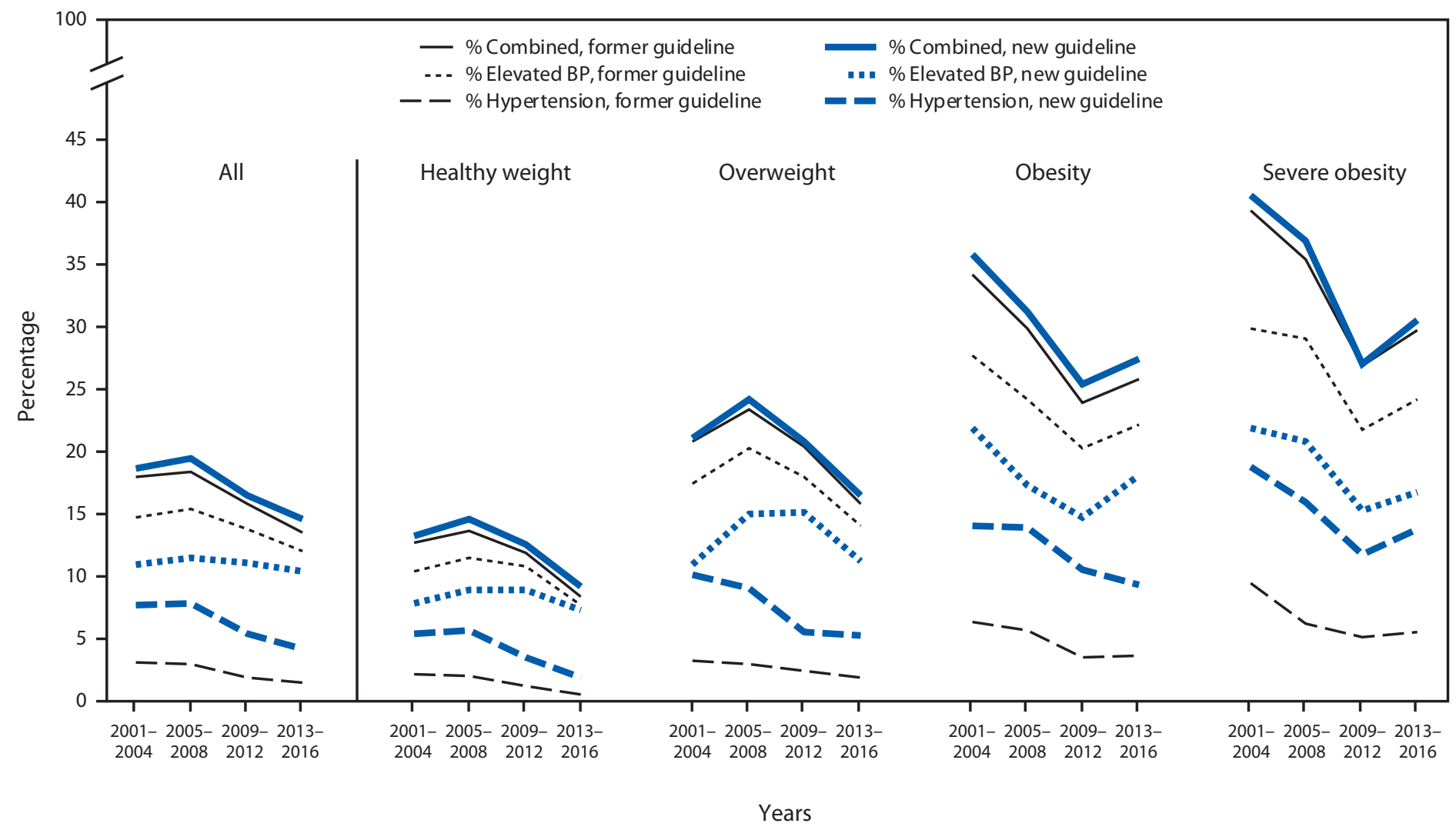

net increase, and males would account for over two thirds. Nearly half of the net increase in new diagnoses of hypertension among youths would be among those with obesity (Table 2), although less than one quarter of U.S. youths have obesity (Table 1).

\section{Discussion}

According to the criteria of the 2017 AAP Clinical Practice Guideline, approximately one in seven U.S. youths aged 12-19 years had elevated BP or hypertension during 20132016. Prevalence of hypertension varied by weight status, ranging from $2 \%$ among healthy-weight youths to nearly $14 \%$ among those with severe obesity. The new guideline used a lower threshold of hypertension and new percentile references, and compared with the former guideline, the new guideline would reclassify $2.6 \%$ of U.S. youths, or nearly an additional 800,000 , as having hypertension.

The application of the new guideline results in a net increase in the number of persons aged 12-19 years classified as having hypertension. Early screening (3) and intervention should be encouraged. Hypertension among youths is associated with increased risk for hypertension and other markers of cardiovascular risk during adulthood $(1,2)$; however, if children with hypertension can achieve normal BP by adulthood, this risk might be reduced (1). Despite significant increases in the prevalence of obesity and severe obesity from 2001-2004 to 2013-2016, the prevalence of hypertension declined significantly (3.5 percentage points) across this time. This decline in adolescent hypertension is consistent with other reports $(6,7)$, and might be related to improved diet quality or improved screening and earlier lifestyle or pharmacologic intervention $(8,9)$. Increases in antihypertensive medication use, and subsequent decreases in BP, might have partially contributed to the observed declines in hypertension. Information on medication use was not available for participants aged 12-15 years and thus could not be included in the definition of hypertension for this age group. In addition, there appeared to be an increase in antihypertensive medication use based on review of the participants' actual medications, both among youths who selfreported medication use for BP control and were collected in the definition of hypertension, and among youths who did not self-report medication use for BP control and were not included in the definition of hypertension. Although antihypertensive, or BP-lowering, medications are primarily used to manage hypertension, they can also be used for other cardiovascular conditions, migraines, or anxiety. Declines in adolescent 
TABLE 2. Estimated hypertension prevalence and population classification by new* and former ${ }^{\dagger}$ guidelines — National Health and Nutritional Examination Survey 2013-2016

\begin{tabular}{|c|c|c|c|c|c|c|c|}
\hline Characteristic (no.) & No. (weighted) & $\begin{array}{c}\text { Estimated } \\
\text { hypertension } \\
\text { prevalence } \\
\text { (new guidelines) } \\
\%(95 \% \mathrm{Cl})\end{array}$ & $\begin{array}{l}\text { Hypertension } \\
\text { prevalence } \\
\text { (former guidelines } \\
\%(95 \% \mathrm{Cl})\end{array}$ & $\begin{array}{l}\text { No. of persons } \\
\text { with } \\
\text { hypertension } \\
\text { (new } \\
\text { guidelines) }\end{array}$ & $\begin{array}{c}\text { No. of persons } \\
\text { with } \\
\text { hypertension } \\
\text { (former } \\
\text { guidelines) }\end{array}$ & $\begin{array}{c}\text { Net increase in } \\
\text { no. of persons } \\
\text { with } \\
\text { hypertension }\end{array}$ & $\begin{array}{l}\text { Percentage of } \\
\text { population } \\
\text { reclassified as } \\
\text { having } \\
\text { hypertension }\end{array}$ \\
\hline All, aged $12-19$ yrs $(2,440)$ & $30,855,000$ & $4.11(3.22-5.24)$ & $1.54(1.01-2.23)$ & $1,269,000$ & 474,000 & 795,000 & $2.58(1.84-3.34)$ \\
\hline \multicolumn{8}{|l|}{ Age group (yrs) } \\
\hline $12-17(1,898)$ & $24,352,000$ & $3.21(2.40-4.28)$ & $1.62(0.97-2.52)$ & 781,000 & 394,000 & 387,000 & $1.59(0.95-2.29)$ \\
\hline $18-19(542)$ & $6,503,000$ & $7.50(5.00-10.73)$ & $1.23(0.48-2.56)$ & 488,000 & 80,000 & 408,000 & $6.29(3.98-8.93)$ \\
\hline \multicolumn{8}{|l|}{ Sex } \\
\hline Male $(1,220)$ & $15,550,000$ & $5.78(4.33-7.67)$ & $2.18(1.39-3.25)$ & 899,000 & 339,000 & 560,000 & $3.62(2.35-5.00)$ \\
\hline Female $(1,220)$ & $15,305,000$ & $2.42(1.41-3.84)$ & $0.88(0.44-1.58)$ & 370,000 & 135,000 & 235,000 & $1.53(0.88-2.32)$ \\
\hline \multicolumn{8}{|l|}{ Race/Ethnicity } \\
\hline White, non-Hispanic (641) & $16,669,000$ & $2.97(1.73-4.74)$ & $0.80^{\text {I }}(0.21-2.08)$ & 495,000 & 133,000 & 362,000 & $2.17(1.09-3.43)$ \\
\hline Black, non-Hispanic (583) & $4,345,000$ & 6.27 (3.84-9.59) & $2.94(1.44-5.30)$ & 273,000 & 128,000 & 145,000 & $3.37(1.89-5.05)$ \\
\hline Mexican American (549) & $4,525,000$ & $4.94(3.01-7.59)$ & 2.33 (1.19-4.09) & 224,000 & 106,000 & 118,000 & $2.58(1.29-4.04)$ \\
\hline Other (667) & $5,315,000$ & $5.22(3.65-7.20)$ & $2.02(1.09-3.40)$ & 277,000 & 107,000 & 170,000 & $3.23(1.86-4.79)$ \\
\hline \multicolumn{8}{|l|}{ Weight status $§$} \\
\hline Healthy $(1,423)$ & $18,439,000$ & $1.88(1.12-2.97)$ & $0.62^{\text {ๆ }}(0.28-1.18)$ & 347,000 & 114,000 & 234,000 & $1.28(0.63-2.11)$ \\
\hline Overweight (461) & $5,689,000$ & $1.86(0.83-3.55)$ & $1.86(0.83-3.55)$ & 287,000 & 106,000 & 181,000 & $3.16^{\text {ๆ }}(1.38-5.40)$ \\
\hline Obesity (all) (556) & $6,726,000$ & $9.43(6.78-12.97)$ & $3.79(2.20-6.04)$ & 634,000 & 255,000 & 380,000 & $5.64(3.66-7.88)$ \\
\hline Obesity (severe) (228) & $2,705,000$ & $14.70(10.01-20.51)$ & $5.87(3.20-9.76)$ & 397,000 & 159,000 & 239,000 & $8.76(4.68-13.93)$ \\
\hline Obesity (not severe) (328) & $4,022,000$ & $5.89(2.91-10.44)$ & $2.38(0.66-5.96)$ & 237,000 & 96,000 & 141,000 & $3.52(1.84-5.52)$ \\
\hline
\end{tabular}

Abbreviations: $\mathrm{BMI}=$ body mass index; $\mathrm{Cl}=$ confidence interval.

* New guideline: adolescents aged 12-17 years were classified as having hypertension if mean systolic or diastolic blood pressure was $\geq 95$ th percentile (using 2017 percentile tables), or systolic blood pressure was $\geq 130 \mathrm{mmHg}$, or diastolic blood pressure was $\geq 80 \mathrm{mmHg}$, or the participant reported were taking antihypertensive medication (available for ages 16-19 years). Persons aged 18-19 years were classified as having hypertension if systolic blood pressure was $\geq 130 \mathrm{mmHg}$, or diastolic blood pressure was $\geq 80 \mathrm{mmHg}$, or if the participant reported taking antihypertensive medication.

${ }^{\dagger}$ Former guideline: adolescents aged 12-17 years were classified as having hypertension if mean systolic or diastolic blood pressure was $\geq 95$ th percentile (using 2004 age, sex, and height percentile tables), or if the participant reported use of antihypertensive medication. For persons aged 18-19 years, hypertension was defined as systolic blood pressure was $\geq 140 \mathrm{mmHg}$, or diastolic blood pressure was $\geq 90 \mathrm{mmHg}$, or if the participant reported use of antihypertensive medication.

$\S \mathrm{BMI}$ is compared with age- and sex-specific reference values from the 2000 CDC growth charts (https://www.cdc.gov/growthcharts/cdc_charts.htm). Healthy $=$ BMIfor-age $\geq 5$ th to $<85$ th, overweight $=$ BMI-for-age $\geq 85$ th to $<95$ th percentile, obesity $=$ BMI-for-age $\geq 95$ th percentile. Severe obesity $=$ BMI-for-age $\geq 120 \%$ of the 95 th percentile. Those classified as underweight are excluded.

II Indicates relative standard error $>30 \%$.

hypertension prevalence should be interpreted with caution, as the underlying causes of the decline are uncertain $(7)$.

The findings in this report are subject to at least three additional limitations. First, surveys such as NHANES are subject to selection and response bias, which might affect the accuracy of national estimates, despite use of weights and survey procedures. Second, multiple BP measurements were taken on a single day, rather than spread over two or more visits as is recommended for diagnosis (3). Finally, self-reported medication use data are subject to recall bias.

Reducing hypertension prevalence among youths is a Healthy People 2020 objective (HDS-5.2).99 Lifestyle interventions for youths with elevated BP or hypertension include increased physical activity and adoption of healthy eating patterns such as the Dietary Approaches to Stop Hypertension (DASH) diet (3). Sodium reduction in the food supply and promotion of physical activity in communities and schools are population strategies for improving cardiovascular health

\footnotetext{
99 https:/www.healthypeople.gov/2020/topics-objectives/topic/heart-diseaseand-stroke/objectives.
}

(10). Pediatricians, family physicians, public health professionals, policy makers, parents, and schools can all be involved in efforts to address hypertension in the adolescent population.
Summary
What is already known about this topic?
Elevated blood pressure during adolescence is associated with cardiovascular risk in adulthood. In 2017, the American Academy of Pediatrics released a new guideline that changed the criteria for diagnosing hypertension.
What is added by this report?
Using the new guideline, an estimated 800,000 additional youths aged 12-19 years (especially older youths, males, and those with obesity) would be reclassified as having hypertension during 2013-2016, compared with using the former guideline.
What are the implications for public health practice?
Clinicians and researchers transitioning to the new guideline might expect more youths to be classified as having hyperten- sion. Efforts to address hypertension in youths include lifestyle and environmental strategies that promote cardiovascular health. 


\section{Conflict of Interest}

No conflicts of interest were reported. ${ }^{1}$ Division for Heart Disease and Stroke Prevention, National Center for Chronic
Disease Prevention and Health Promotion, CDC; ${ }^{2}$ United States Public Health
Service; ${ }^{3}$ Division of Nutrition, Physical Activity, and Obesity, National Center
for Chronic Disease Prevention and Health Promotion, CDC.

Corresponding author: Sandra L. Jackson, SLJackson@cdc.gov, $770-488-4221$.

\section{References}

1. Juhola J, Magnussen CG, Berenson GS, et al. Combined effects of child and adult elevated blood pressure on subclinical atherosclerosis: the International Childhood Cardiovascular Cohort Consortium. Circulation 2013;128:217-24. https://doi.org/10.1161/ CIRCULATIONAHA.113.001614

2. Chen X, Wang Y. Tracking of blood pressure from childhood to adulthood: a systematic review and meta-regression analysis. Circulation 2008;117:3171-80. https://doi.org/10.1161/ CIRCULATIONAHA.107.730366

3. Flynn JT, Kaelber DC, Baker-Smith CM, et al.; Subcommittee on Screening and Management of High Blood Pressure in Children. Clinical practice guideline for screening and management of high blood pressure in children and adolescents. Pediatrics 2017;140:e20171904. https:// doi.org/10.1542/peds.2017-1904

4. Sharma AK, Metzger DL, Rodd CJ. Prevalence and severity of high blood pressure among children based on the 2017 American Academy of Pediatrics Guidelines. JAMA Pediatr 2018;172:557-65. https://doi. org/10.1001/jamapediatrics.2018.0223
5. Flegal KM, Wei R, Ogden CL, Freedman DS, Johnson CL, Curtin LR. Characterizing extreme values of body mass index-for-age by using the 2000 Centers for Disease Control and Prevention growth charts. Am J Clin Nutr 2009;90:1314-20. https://doi.org/10.3945/ajcn.2009.28335

6. Kit BK, Kuklina E, Carroll MD, Ostchega Y, Freedman DS, Ogden CL. Prevalence of and trends in dyslipidemia and blood pressure among US children and adolescents, 1999-2012. JAMA Pediatr 2015;169:272-9. https://doi.org/10.1001/jamapediatrics.2014.3216

7. Yang Q, Zhong Y, Merritt R, Cogswell ME. Trends in high blood pressure among United States adolescents across body weight category between 1988 and 2012. J Pediatr 2016;169:166-73.e3. https://doi. org/10.1016/j.jpeds.2015.10.007

8. Gu X, Tucker KL. Dietary quality of the US child and adolescent population: trends from 1999 to 2012 and associations with the use of federal nutrition assistance programs. Am J Clin Nutr 2017;105:194-202. https://doi.org/10.3945/ajcn.116.135095

9. George MG, Tong X, Wigington C, Gillespie C, Hong Y. Hypertension screening in children and adolescents-National Ambulatory Medical Care Survey, National Hospital Ambulatory Medical Care Survey, and Medical Expenditure Panel Survey, United States 2007-2010. MMWR Suppl 2014;63(No. Suppl 2).

10. Lloyd-Jones DM, Hong Y, Labarthe D, et al.; American Heart Association Strategic Planning Task Force and Statistics Committee. Defining and setting national goals for cardiovascular health promotion and disease reduction: the American Heart Association's strategic impact goal through 2020 and beyond. Circulation 2010;121:586-613. https:// doi.org/10.1161/CIRCULATIONAHA.109.192703 